\title{
Seasonal Văriations of Activities of Glycogen-degrading Enzymes in Ascidian Muscle
}

\author{
Aditep Nontratip and Hideaki Yamanaka \\ Department of Food Science and Technology, Tokyo University of Fisheries, Konan, Minato, Tokyo 108, Japan \\ (Received June 30, 1993)
}

\begin{abstract}
The activities of $\alpha$-amylase, $\alpha$-glucosidase, hexokinase (HK), phosphoglucomutase (PGM), and phosphorylase were determined monthly in fresh ascidian muscle and changes of glycolytic compounds during storage at $2^{\circ} \mathrm{C}$ were investigated bimonthly.

Most of the enzymatic activities were lowest in summer and highest in winter. $\alpha$-Glucosidase, HK, and PGM showed conspicuous changes seasonally while $\alpha$-amylase and phosphorylase showed slight ones. Glycogen in fresh ascidian muscle was highest in summer and lowest in winter wherease glucose showed a seasonal change in the opposite manner. Glucose 6-phosphate, fructose 6-phosphate, and lactic acid in fresh muscle fluctuated throughout the year and their seasonal variations were obscure. During storage, glycogen was degraded and other metabolites in question accumulated. The degradation of glycogen and the accumulations of glucose and lactic acid were noticeably faster in winter than in summer. These findings suggest that ascidian adapts enzymatically to environmental changes, especially to attain certain catalytic efficiency in winter and, as a result, that high enzymatic activities in winter can enhance rapid postmortem changes in the ascidian muscle.
\end{abstract}

Key words: seasonal variation, ascidian, amylase, glycogen, glucosidase, hexokinase, glucose, lactic acid.

Several studies on seasonal variations of extractive components in ascidian muscle are well documented. ${ }^{1-4)}$ Still, not much progress has been made in enzymatic features. Information on the seasonal variation of enzymatic activity has been obtained for short-necked clam, ${ }^{5)}$ revealing a negative correlation between lysozyme activity and glycogen content. In view of physiology and biochemistry, the environmental temperature is considered to be a factor affecting the enzymatic activity. The adaptation of myofibrillar ATPase to habitat temperature has been illustrated in carp ${ }^{6)}$ and Antarctic fish ${ }^{7,8)}$ and is related to an evolutionary response to attain high catalytic efficiency at low temperatures. It is noted that ascidian experiences fluctuations of habitat temperature throughout the year, and the annual change of environmental condition can result to some extent in the contents of the muscle constituents. The authors have recently reported the seasonal variation of glycogen ${ }^{9)}$ and the existence of amylolytic and glycolytic pathways ${ }^{10}$ in ascidian muscle. Since the metabolism of glycogen directly involves enzymatic action, the seasonal variation of this compound raises an intriguing question about seasonal changes in the activities of pertinent enzymes and other metabolites.

In this study, we are primarily concerned with whether ascidian muscle possesses seasonal changes in the activities of glycogen-degrading enzymes. The authors detected monthly activities of $\alpha$-amylase (EC 3.2.1.1), $\alpha$-glycosidase (EC 3.2.1.20), hexokinase (HK, EC 2.7.1.1), phosphorylase (EC 2.4.1.1), and phosphoglucomutase (PGM, EC 5.4.2.2) in ascidian muscle. Since these enzymes are involved in the postmortem biochemical changes which can be apparently perceived a few days after storage at $2^{\circ} \mathrm{C},{ }^{9)}$ the authors also investigated postmortem glycolysis under this condition bimonthly as a connected study.

\section{Materials and Methods}

\section{Samples}

Four live specimens of ascidian Halocynthia roretzi cultured in Miyagi Prefecture were obtained from Tokyo Central Wholesale Market and submitted to the laboratory monthly from May 1992 to April 1993. After the removal of tunic and evisceration, the muscle was cut into small pieces and mixed. The crude enzyme was prepared as reported by Yamanaka ${ }^{11}$ and the determination of enzymatic activity was undertaken at optimum $\mathrm{pH}$ and $\mathrm{pH} 6.4$ (muscular $\mathrm{pH})^{10)}$ as stated below. During this study, another four specimens were submitted bimonthly from June 1992 to April 1993 for the investigation of postmortem glycolysis. The muscle obtained from the same procedure mentioned above was stored at $2^{\circ} \mathrm{C}$ for 2 days. The withdrawal of muscle was conducted 0,1 , and 2 days after storage and the extraction was carried out as described previously. ${ }^{9)}$

Determination of Activity of $\alpha$-Amylase

The activity of $\alpha$-amylase at $\mathrm{pH} 6.4$ (muscular $\mathrm{pH}$ ) and $\mathrm{pH} 7.0$ (optimum $\mathrm{pH})$ was determined according to the method of Bergmeyer et al. ${ }^{121}$ After incubation of the assay mixture for $120 \mathrm{~min}$, the resultant maltose was reacted with 3,5-dinitrosalicylic acid and detected colorimetrically at $546 \mathrm{~nm}$.

\section{Determination of Activity of $\alpha$-Glucosidas}

Based on the method of Bergmeyer et al., ${ }^{12)}$ the activity of $\alpha$-glucosidase was measured at muscular $\mathrm{pH}$ and 5.0 (optimum $\mathrm{pH}$ ). After incubation of the assay mixture for $120 \mathrm{~min}$, the resultant glucose was determined with hexokinase and glucose 6-phosphate (G6P) dehydrogenase on the basis of the optical increment of NADPH at $340 \mathrm{~nm}$.

Determination of Activity of Hexokinase ( $H K$ )

According to the method reported by Yamanaka, ${ }^{11}$ crude enzyme solution was added into the assay mixture to let $\mathrm{HK}$ react with glucose at muscular $\mathrm{pH}$ and $\mathrm{pH} 8.0$ (optimum $\mathrm{pH}$ ). The rate of G6P formation was determined with G6P dehydrogenase colorimetrically at $340 \mathrm{~nm}$.

\section{Determination of Activity of Phosphoglucomutase ( $P G M)$}

The activity of PGM at muscular $\mathrm{pH}$ and $\mathrm{pH} 7.5$ (optimum $\mathrm{pH}$ ) was determined according to the method reported by Yamanaka. ${ }^{11)}$ PGM in the crude enzyme converted glucose 1-phosphate (G1P) to G6P and the 
rate of G6P formation was determined as aforementioned

Determination of Activity of Phosphorylase

Based on the method reported by Yamanaka, ${ }^{11}$ the activity of phosphorylase was determined at muscular $\mathrm{pH}$ and $\mathrm{pH} 7.0$ (optimum $\mathrm{pH}$ ). Phosphorylase in the crude enzyme converted glycogen to G1P and the rate of GIP formation was determined with PGM and G6P dehydrogenase spectrophotometrically by monitoring the increase in absorbance at $340 \mathrm{~nm}$ as a function of time.

Determination of Water-Soluble Protein

The protein content in the crude enzyme solution was determined with phenol reagent according to the method of Lowry et al. ${ }^{13}$ )

\section{Determination of Glycogen and Free Glucose}

According to the method of Keppler and Decker, ${ }^{14)}$ free glucose was determined with HK and G6P dehydrogenase on the basis of the increment in optical density of NADPH at $340 \mathrm{~nm}$. Glycogen was hydrolyzed with amyloglucosidase and the resultant glucose was determined in the same manner.

Determination of Glucose 6-Phosphate (G6P) and Fructose 6-Phosphate (F6P)

G6P and F6P were determined by the method of Racker ${ }^{151}$ with G6P dehydrogenase on the basis of the increment in optical density of NADPH at $340 \mathrm{~nm}$. F6P was converted to G6P with glucosephosphate isomerase and then determined as stated above.

\section{Determination of Lactic Acid}

Lactic acid was determined with lactate dehydrogenase according to the method of Gutmann and Wahlefeld. ${ }^{16)}$

\section{Results}

Seasonal Variations in the Activities of Glycogen Degrading Enzymes

Seasonal variations of enzymatic activities at muscular $\mathrm{pH}$ and optimum pHs are shown in Figs. 1 and 2, respectively. In general, the activities were on the decline at the onset of study and reached their lowest levels in August and/or September. The activities increased subsequently to their highest levels in February and/or March. These changes were conspicuously observed in $\alpha$ glucosidase, HK, and PGM. As shown in Fig. 1, $\alpha$-amylase and PGM possessed high activities while $\mathrm{HK}$ and phosphorylase possessed low activities at muscular $\mathrm{pH}$ throughout the year. The activity of PGM was most prominent except in the period between August and November when it dropped to a degree lower than that of $\alpha$-amylase. The maximum activities of $\alpha$-amylase, $\alpha$ glucosidase, $\mathrm{HK}$, phosphorylase, and PGM at muscular $\mathrm{pH}$ were $23.90,0.95,0.45,0.52$, and 38.10 units $/ \mathrm{g}$ protein, respectively. On the other hand, the minimum ones were $14.20,0.33,0.11,0.03$, and 6.90 units/g protein in the order mentioned. Apparently, the seasonal changes in the activities of all enzymes were not proportional to one another. PGM showed 23-260 times higher activity than phosphorylase. $\alpha$-Amylase and $\alpha$-glucosidase showed 53-129 times and 2-4 times higher activities than $\mathrm{HK}$, respectively.

Seasonal variations in the activities at optimum $\mathrm{pHs}$, shown in Fig. 2, are similar to those at muscular pH. $\alpha$-Glucosidase, HK, and PGM showed obvious changes in seasonal activities as stated above while $\alpha$-amylase and phosphorylase showed slight ones. The maximum activities of $\alpha$-amylase, $\alpha$-glucosidase, HK, phosphorylase, and PGM were $26.10,5.18,5.80,0.96$, and 66.80 units/g protein,

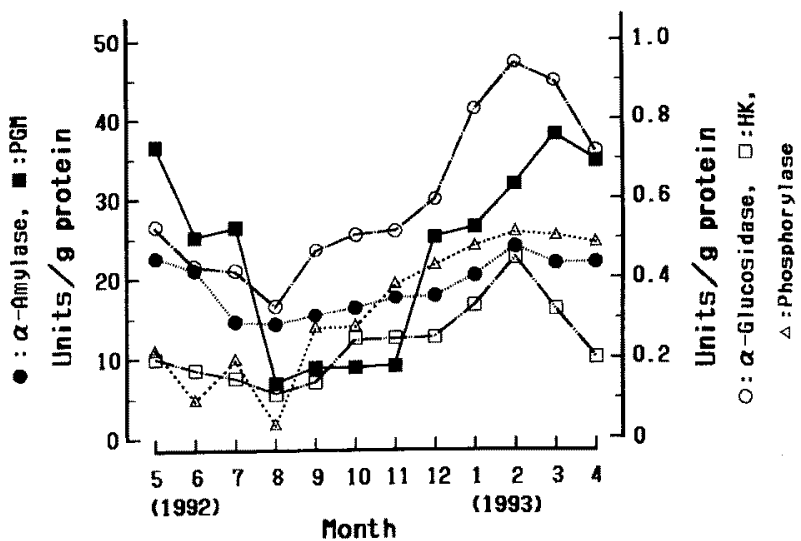

Fig. 1. Seasonal variations in the activities of glycogen-degrading enzymes in ascidian muscle at muscular $\mathrm{pH}$.

HK, hexokinase; PGM, phosphoglucomutase.

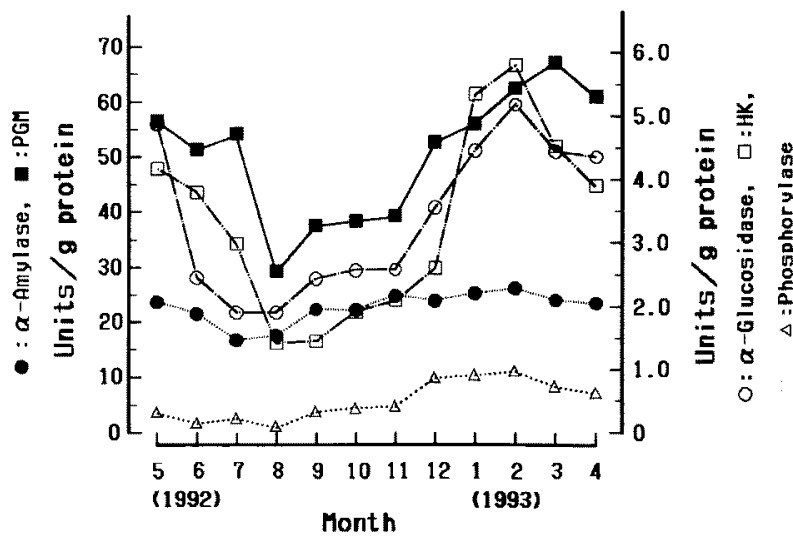

Fig. 2. Seasonal variations in the activities of glycogen-degrading enzymes in ascidian muscle at optimum pHs.

HK, hexokinase; PGM, phosphoglucomutase.

respectively, while the minimum ones were $16.80,1.90,1.43$, 0.07 , and 29.10 units/g protein in the order mentioned.

\section{Seasonal Variations in Glycolytic Compounds and Post- mortem Changes}

Seasonal variations of glycogen and its change during storage are shown in Fig. 3. The content of glycogen in the fresh muscle of ascidian clearly showed seasonal variation. It was highest in August $(7.5 \% \mathrm{w} / \mathrm{w})$ and lowest in February $(3.0 \% \mathrm{w} / \mathrm{w})$. During storage at $2^{\circ} \mathrm{C}$, glycogen decreased rather faster in winter than in summer.

Seasonal variations of glucose and its change during storage are shown in Fig. 4. The glucose content in the fresh muscle of ascidian was lowest in August $(13.2 \mathrm{mg} / 100 \mathrm{~g})$ and highest in February $(25.3 \mathrm{mg} / 100 \mathrm{~g})$. The seasonal variation of this compound was apparently the reverse of that of glycogen. During storage, glucose increased markedly, the increase being fastest in February and slowest in August.

Figures 5 and 6 show seasonal variations in contents and postmortem changes of G6P and F6P, respectively. The contents of G6P and F6P in the fresh muscle of ascidian fluctuated in the range of $3.3-10.7$ and $1.2-3.4 \mathrm{mg} / 100 \mathrm{~g}$ respectively. Seasonal variations of both compounds were 


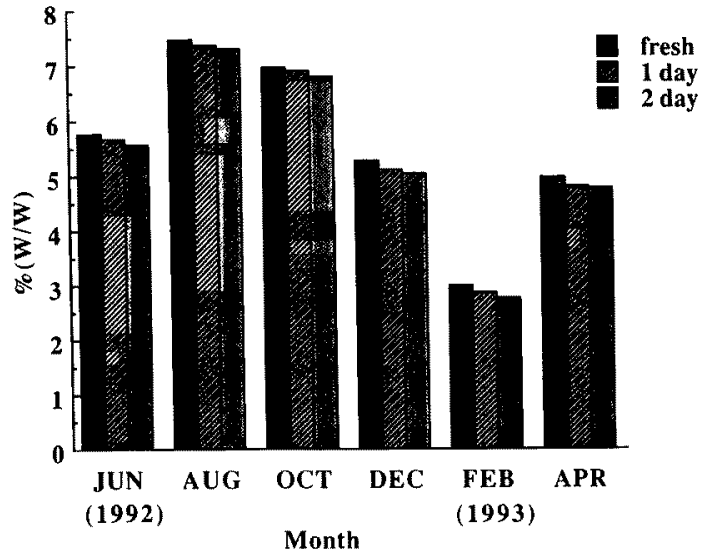

Fig. 3. Seasonal variations in glycogen content in ascidian muscle during storage at $2^{\circ} \mathrm{C}$

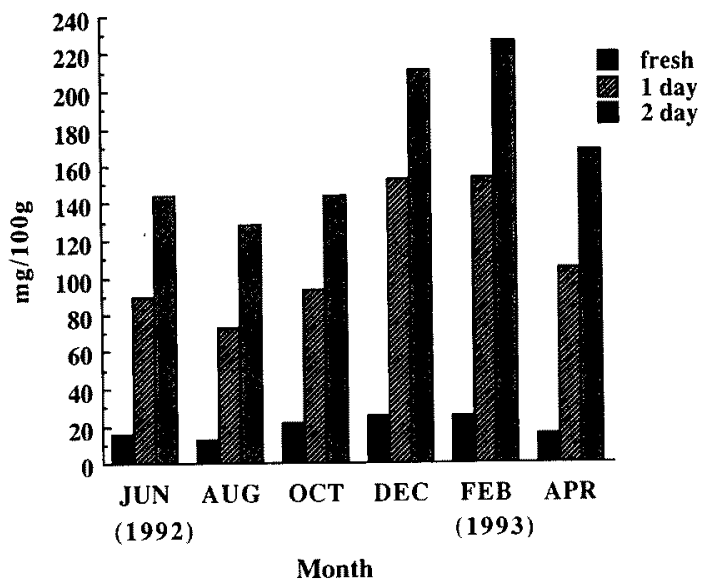

Fig. 4. Seasonal variations in glucose content in ascidian muscle during storage at $2^{\circ} \mathrm{C}$

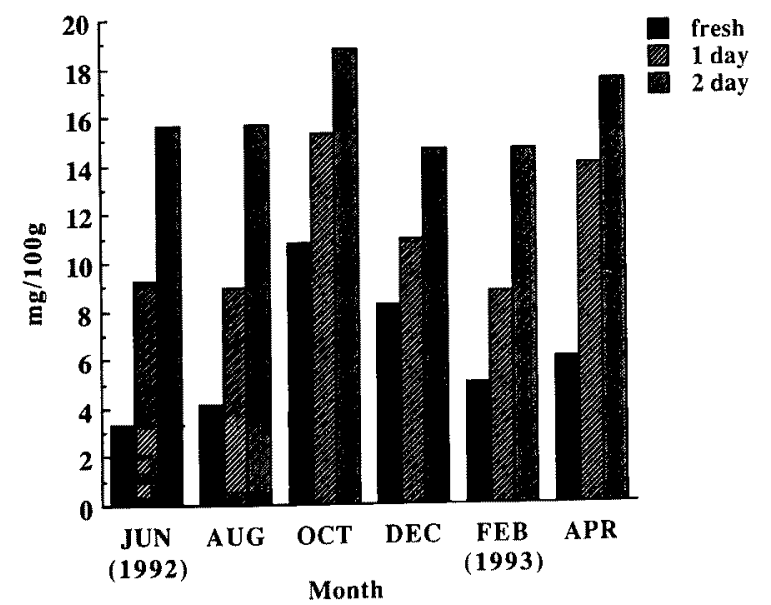

Fig. 5. Seasonal variations in G6P content in ascidian muscle during storage at $2^{\circ} \mathrm{C}$

obscure. During storage undertaken bimonthly, these compounds were accumulated to various degrees irrespective of season.

Seasonal variations of lactic acid and its change during

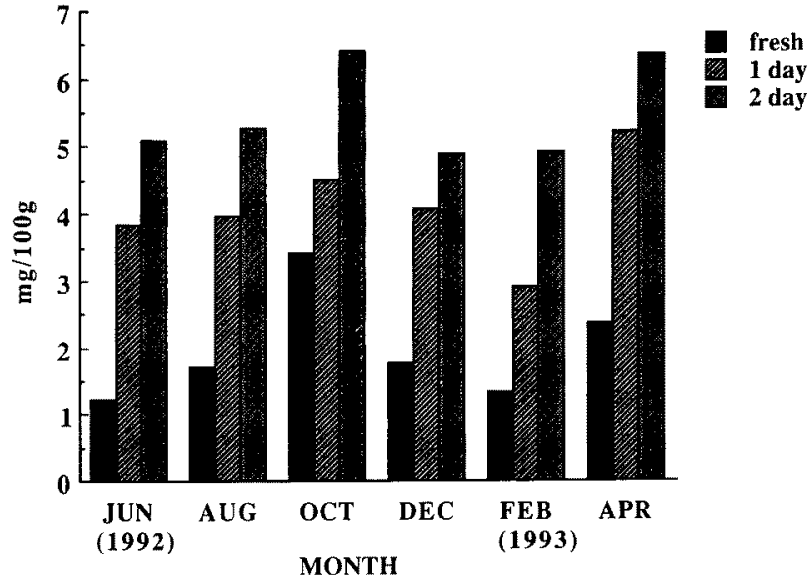

Fig. 6. Seasonal variations in $\mathrm{F} 6 \mathrm{P}$ content in ascidian muscle during storage at $2^{\circ} \mathrm{C}$.

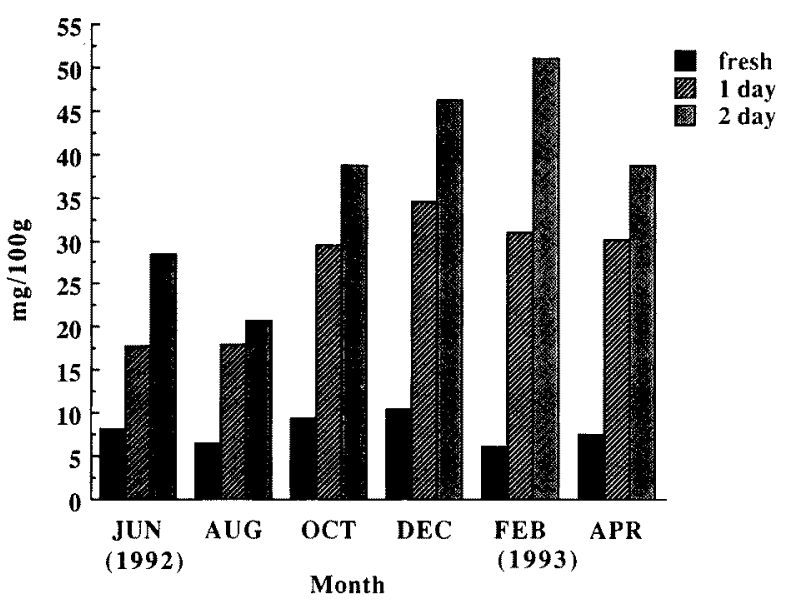

Fig. 7. Seasonal variations in lactic acid content in ascidian muscle during storage at $2^{\circ} \mathrm{C}$.

storage are shown in Fig. 7. The content of lactic acid in the fresh muscle of ascidian fluctuated in the range of $6.0-10.4 \mathrm{mg} / 100 \mathrm{~g}$ and its seasonal variation was not clear. During storage, the accumulation of this compound was highest in February and lowest in August.

\section{Discussion}

The activities of glycogen-degrading enzymes in ascidian muscle were apparently in inverse relation to the glycogen content. In summer, the enzymatic activities dropped and glycogen was accumulated to the highest level $(7.5 \% \mathrm{w} / \mathrm{w})$. In contrast, the activities rose and glycogen was lowest $(3.0 \% \mathrm{w} / \mathrm{w})$ in winter. Similar findings have been reported on the negative correlation between lysozyme activity and glycogen content in the short-necked clam. ${ }^{5)}$ The seasonal changes of enzymatic activities suggested that ascidian adapted physiologically and biochemically to environmental temperature changes. Especially, the increases in enzymatic activities in winter may be related to the adaptable mechanism to achieve certain catalytic efficiency in ascidian at low temperature. 
Several adaptations to environmental temperature have been observed in fish. ${ }^{6-8,17)}$ Heap et al. ${ }^{18}$ found that cold acclimation of carp, tench, and roach to $10^{\circ} \mathrm{C}$ resulted in higher myofibrillar ATPase activity than warm acclimation to $28^{\circ} \mathrm{C}$. They also showed that re-acclimation of carp between these two temperatures caused the reverse of myofibrillar ATPase activity, perceivable within 4 weeks, and suggested that seasonal adaptation to environmental temperatures was possible to maintain locomotory efficiency. Baslow and Nigrelli ${ }^{19)}$ observed that the brain cholinesterase activity of killifish varied in inverse proportion to the ambient temperature and explained the enzymatic adaptation by using the $Q$ factor (a factor for an increase in enzymatic activity with a rise in temperature).

The temperature adaptation of enzymes has been explained in many ways. The increased activities of cytochrome oxidase and succinic dehydrogenase in cold acclimated goldfish were related to alterations in the quantity rather than the quality of the enzymes. ${ }^{20.21)}$ In view of qualitative adaptation, it has been reported that the higher catalytic efficiencies between homologous enzyme systems from cold adapted poikilotherms compared with homoeotherms may be explained in terms of an increase in weak bond formation of the activated enzyme-substrate complex in poikilotherms. ${ }^{22)}$ Johnston et al. ${ }^{8)}$ suggested that the higher activity of myofibrillar ATPase of Antarctic fish at low environmental temperatures was associated with weaker bonding; in other words, with a more open molecular structure. Watabe et al. ${ }^{23)}$ observed differences in cytosolic protein between cold and warm acclimated goldfish and carp, which could be regarded as a strategy in response to environmental temperature changes. Low et al. ${ }^{24)}$ explained the high efficiency of ectothermic enzymes when compared with homologous enzymes of birds and mammals in terms of thermodynamic parameters, i.e. enthalpy, entropy, and free energy of activation. Thus far, it seems that there are a number of factors which could conceivably act to regulate the adaptation of enzymes. In this study, it is observed that the seasonal changes of enzymatic activities in ascidian muscle differed to varying degrees. $\alpha$-Glucosidase, $\mathrm{HK}$, and PGM showed noticeable changes whereas $\alpha$-amylase and phosphorylase showed slight ones. This may be due to the differences in activity-regulating factors which are still unknown.

Seasonal variations in glycogen in this study were concordant with our previous report, ${ }^{9}{ }^{9}$ except that the highest and lowest levels were somewhat different and that glycogen in this study showed a smaller extent of variation. Seasonal variations in glucose went in the opposite direction to those of glycogen. During storage at $2^{\circ} \mathrm{C}$, the decrease in glycogen and the increase in glucose in summer were relatively slow when compared with the changes in winter. This was mostly due to seasonal changes in enzymatic activities. In summer, when the activities of glycogendegrading enzymes were low, glycogen was degraded slowly, resulting in a low accumulation of glucose. In winter, when the enzymatic activities were high, glycogen was degraded quite rapidly and glucose was accumulated to a high level.

It is also noted that the obvious rise in HK activity in winter might result in the rapid glucose depletion in postmortem samples obtained in this season. However, it turned out as aforementioned that the postmortem accumulation of glucose was faster in winter than in summer. This can be explained by the degree of activity increase. The HK activity increased from 0.11 units/g protein in summer to 0.45 units $/ g$ protein in winter. In contrast, the $\alpha$-glucosidase activity increased from 0.33 to 0.95 units/g protein and the $\alpha$-amylase activity from 14.2 to 23.9 units/g protein when considered in the same manner. It is apparent that the formation of glucose in postmortem ascidian muscle was always greater than the depletion of this compound. Moreover, the difference between the formation and the depletion of glucose was more noticeable in winter than in summer. Thus, it is considered that although the HK activity increased 4 times from summer to winter, the postmortem accumulation of glucose was faster in winter than in summer. On account of the high accumulation of glucose and high activities of $\alpha$-amylase and $\alpha$-glucosidase when compared with phosphorylase throughout the year, the authors confirm the previous findings ${ }^{9.10)}$ that the amylolytic pathway is the main route for glycogen degradation in postmortem ascidian muscle.

The contents of G6P and F6P in the fresh muscle of ascidian fluctuated throughout the year and their seasonal variations could not be observed. During storage, these compounds increased to various degrees and their accumulations were no higher in winter than in summer, although the activity of $\mathrm{HK}$ rose in winter. In this regard, ATP is taken into consideration as the formation of G6P from glucose can be accomplished at the expense of this compound. Early studies ${ }^{2,3)}$ showed that ATP in ascidian muscle fluctuated at a low level irrespective of the season. The authors hereby assume that the fluctuation in the ATP content may be responsible for seasonal fluctuations and irregular postmortem changes in G6P and F6P.

The content of lactic acid in the fresh muscle of ascidian fluctuated in a narrow range throughout the year and no seasonal variation could be seen. This is in agreement with a finding (unpublished data) that the $\mathrm{pH}$ of fresh ascidian muscle is always close to 6.4. The highest accumulation of lactic acid in winter and the lowest in summer during storage may possibly result from the faster degradation of glycogen in winter than in summer. It has been stated that a stoichiometric relation between glycogen lost and lactic acid formed is not always observed. ${ }^{25}$ ) However, the authors noticed in this study that a high accumulation of lactic acid coincided with a rapid degradation of glycogen. Seasonal changes in enzymatic activities should also be taken into consideration. The temperature-dependent adaptations of lactate dehydrogenase ${ }^{24,26)}$ and D-glyceraldehyde 3-phosphate dehydrogenase ${ }^{24)}$ have been observed in fish. Thus, it is possible that glycolytic enzymes in ascidian muscle other than those in this study may also be adaptable and that the high rate of glycolysis in winter may confer advantages on metabolic efficiency in ascidian.

Apparently, seasonal variations in enzymatic activities can affect the progress of postmortem biochemical changes. These findings lead to a hypothesis that the loss of freshness in ascidian muscle may vary with the season. Additionally, it is considered that the same species of ascidian from different habitat temperatures may show different postmortem changes. 


\section{References}

1) K. Watanabe, H. Maezawa, H. Nakamura, and S. Konosu: Seasonal variation of extractive nitrogen and free amino acids in the muscle of ascidian Halocynthia roretzi. Nippon Suisan Gakkaishi, 49, 1755-1758 (1983).

2) K. Watanabe, H. Uehara, M. Sato, and S. Konosu: Seasonal variation of extractive nitrogenous constituents in the muscle of the ascidian Halocynthia rotetzi. Nippon Suisan Gakkaishi, 51, 1293-1298 (1985).

3) K. Watanabe and S. Konosu: Extractive components of the ascidian Halocynthia roretzi. Kagaku to Seibutsu, 27, 96-103 (1989).

4) C. K. Park, T. Matsui, K. Watanabe, K. Tamaguchi, and S. Konosu: Seasonal variation of extractive nitrogenous constituents in ascidian Halocynthia rotetzi tissues. Nippon Suisan Gakkaishi, 56, 1319-1330 (1990).

5) K. Tokutake, A. Mochizuki, and M. Matsumiya: Seasonal variation of lysozyme activity in short-necked clam. Nippon Suisan Gakkaishi, 58, 1103-1106 (1992).

6) T. Mishima, T. Yokoyama, K. Yano, and M. Tsuchimoto: The influence of rearing water temperature on the properties of $\mathrm{Ca}^{2+}$ - and $\mathrm{Mg}^{2+}$-ATPase activity on carp myofibril. Nippon Suisan Gakkaishi, 56, 477-487 (1990).

7) I. A. Johnston and G. Goldspink: Thermodynamic activation parameters of fish myofibrillar ATPase enzyme and evolutionary adaptions to temperature. Nature, 257, 620-622 (1975).

8) I. A. Johnston, N. J. Walesby, W. Davidson, and G. Goldspink: Temperature adaptation in myosin of Antarctic fish. Nature, 254, 74-75 (1975).

9) A. Nontratip, S. Wada, and H. Yamanaka: Postmortem glycolysis and ATP degradation in the muscle of ascidian Halocynthia roretzi. Nippon Suisan Gakkaishi, 57, 761-766 (1991).

10) A. Nontratip and H. Yamanaka: Activities of glycogen degrading enzymes in ascidian Halocynthia roretzi muscle. Nippon Suisan Gakkaishi, 59, 1265 (1993).

11) H. Yamanaka: Orange discolored meat of canned skipjack-IV. Nippon Suisan Gakkaishi, 41, 217-223 (1975).

12) H. U. Bergmeyer, K. Gawehn, and M. Grassl: Enzymes as biochemical reagents, in "Methods of Enzymatic Analysis" (ed. by H. U. Bergmeyer), Academic Press, New York, 1974, pp. 425-460.
13) O. H. Lowry, N. J. Rosebrough, A. L. Farr, and R, J. Randall: Protein measurement with the folin phenol reagent. J. Biol. Chem., 193, 265-275 (1951).

14) D. Keppler and K. Decker: Glycogen determination with amyloglucosidase, in "Methods of Enzymatic Analysis" (ed. by $\mathrm{H}$ U. Bergmeyer), Academic Press, New York, 1974, pp. 1127-1131.

15) E. Racker: D-Fructose-1,6-diphosphate determination with fructose1,6-diphosphatase, in "Methods of Enzymatic Analysis" (ed. by $\mathrm{H}$. U. Bergmeyer), Academic Press, New York, 1963, pp. 160-163.

16) I. Gutmann and A. W. Wahlefeld: $L-(+)$-Lactate determination with lactate dehydrogenase and NAD, in "Methods of Enzymatic Analysis" (ed. by H. U. Bergmeyer), Academic Press, New York, 1974, pp. 1464-1468.

17) J. R. Hazel and C. L. Prosser: Molecular mechanisms of temperature compensation in poikilotherms. Physiol. Rev., 54, 620-677 (1974).

18) S. P. Heap, P. W. Watt, and G. Goldspink: Consequences of thermal change on the myofibrillat ATPase of five freshwater teleosts. J. Fish Biol., 26, 733-738 (1985).

19) M. H. Baslow and R. F. Nigrelli: The effect of thermal acclimation on brain cholinesterase activity of the killifish, Fundulus heteroclitus. Zoologica, 49, 41-51 (1964).

20) J. Freed: Changes in activity of cytochrome oxidase during adaptation of goldfish to different temperatures. Comp. Biochem. Physiol., 14, 651-659 (1965).

21) J. R. Hazel: The effect of temperature acclimation upon S.D.H. activity from the epaxial muscle of the common goldfish $C$. auratus. Comp. Biochem. Physiol, 43B, 837-861 (1972).

22) P. S. Low and G. N. Somero: Temperature adaptation of enzymes. Comp. Biochem. Physiol., 49B, 307-312 (1974).

23) S. Watabe, K. Kikuchi, and K. Aida: Cold- and warm-temperature acclimation induces specific cytosolic proteins in goldfish and carp. Nippon Suisan Gakkaishi, 59, 151-156 (1993).

24) P. S. Low, J. L. Bada, and G. N. Somero: Temperature adaptation of enzymes. Proc. Nat. Acad. Sci. USA, 70, 430-432 (1973).

25) S. V. Manohar: Postmortem glycolytic and other biochemical changes in white muscle of white sucker (Catostomus commersoni) and northern pike (Esox lucius) at $0^{\circ} \mathrm{C}$. J. Fish. Res. Bd. Canada, 27, 1997-2002 (1970).

26) P. W. Hochachka and G. N. Somero: The adaptation of enzymes to temperature. Comp. Biochem. Physiol., 27, 659-668 (1968). 